Crosslinguistic influence in the acquisition of a third language: The Linguistic Proximity Model

Marit Westergaard ${ }^{1,2}$, Natalia Mitrofanova ${ }^{1}$, Roksolana Mykhaylyk ${ }^{1,3} \&$ Yulia Rodina ${ }^{4}$

1. UiT The Arctic University of Norway, 2. NTNU Norwegian University of Science and

Technology, 3. Harvard University, 4. University of Oslo 


\title{
Crosslinguistic influence in the acquisition of a third language: The Linguistic Proximity Model*
}

\begin{abstract}
Aims and Objectives: The main goal of the present study is to investigate effects of crosslinguistic influence (CLI) in third language acquisition (L3A) by simultaneous bilinguals. We address the following research questions: Do both languages contribute to CLI in L3 acquisition, or is one of them chosen as the sole source of influence? Is CLI always from the typologically more similar language? Is CLI always facilitative, or can it also be non-facilitative?

Methodology: The paper reports on a Grammaticality Judgment Task with two word order conditions, both related to verb movement (verb-second in Norwegian and subject-auxiliary inversion in English).

Data and Analysis: An experiment was carried out with three groups of 11-14-year-old participants, Norwegian-Russian bilinguals $(N=22)$, Norwegian-speaking monolinguals

\footnotetext{
${ }^{*}$ We would like to thank three anonymous reviewers for very helpful comments and suggestions. This research was partly supported by a grant from the Norwegian Directorate for Education and Training as part the program Kompetanse for mangfold, as well as the Research Council of Norway through its Centers of Excellence funding scheme, project number 223265.
} 
$(N=46)$, and Russian-speaking monolinguals $(N=31)$. The data were analyzed using a generalized linear mixed effects logistic regression allowing us to estimate the effects of Condition (Adv-V, Aux-S), Language (Norwegian, Norwegian-Russian, Russian) and their interaction on the Correctness of Judgments.

Findings: The analysis reveals that while L1 Norwegian children over-accept ungrammatical sentences in English with a word order that reflects verb movement (V2), bilingual Norwegian-Russian children notice these errors significantly more often, just like L1 Russians. At the same time, the bilinguals score lower than L1 Russian children on grammatical trials, suggesting the presence of non-facilitative influence from Norwegian. Originality: This study argues for the Linguistic Proximity Model (LPM), which proposes incremental property-by-property learning and allows for both facilitative and nonfacilitative influence from one or both of the previously acquired languages.

Significance: The LPM and supporting experimental data contribute to existing models in L3A by indicating that not just typological proximity but also structural similarity at an abstract level should be considered an important factor in L3A.

Keywords: L3 acquisition, crosslinguistic influence, word order, verb-second, adverb placement, subject-auxiliary inversion, bilingualism, English, Norwegian, Russian 


\section{Introduction}

In recent years, there has been increasing interest in L3 acquisition (L3A) in formal approaches to language, with numerous studies investigating a variety of language combinations (e.g. Leung, 2003; Flynn, Foley \& Vinnitskaya, 2004; Berkes \& Flynn, 2012; Bardel \& Falk, 2007, 2012; Jin, 2009; Montrul, Dias \& Santos, 2011; Rothman \& Cabrielli Amaro, 2010; Rothman, 2011, 2015; Hermas, 2015; Slabakova \& Garcia Mayo, 2015).

Generative L3A has inherited a number of key questions from L2 acquisition (L2A), including the issue of full/partial/no transfer at the initial state of acquisition. However, unlike second language acquisition, L3A occurs in the presence of two potential sources of crosslinguistic influence (CLI) on a subsequently acquired language. The key question in this respect is whether both of the previously learned languages affect L3A, or whether one of the languages is chosen as the primary or sole source of CLI. In the former case, it is typically assumed that the source of influence is determined on a property-by-property basis (cf. Flynn et al., 2004; Berkes \& Flynn, 2012). In the latter case, transfer may be assumed to happen in one fell swoop (cf. Leung, 1998, 2003; Rothman, 2011, 2015). Several factors have been argued to affect the choice of language for CLI, including order of acquisition (cf. Jin, 2009; Na Ranong \& Leung, 2009; Bardel \& Falk, 2007) and 
typological proximity (either perceived psychotypological proximity or similarity at the structural level, cf. Leung, 1998, 2003; Foote, 2009; De Angelis, 2007; Rothman \& Cabrielli Amaro, 2010).

In this paper we discuss some previous models of L3A, starting with those arguing that either the L1 or the L2 has a privileged status with respect to CLI. We then consider models that focus on the role of structural factors, the Cumulative Enhancement Model (CEM; Flynn et al., 2004; Berkes \& Flynn, 2012) and typology-based models such as the Interlanguage Transfer Hypothesis (ITH; e.g. Leung, 1998, 2003) and the Typological Primacy Model (TPM; e.g. Rothman, 2011, 2015). We especially focus on typology-based models, since, in our view, they are currently the most promising and also the most relevant ones to compare to our own model, the Linguistic Proximity Model (LPM). We report on an experimental study examining L3A of English in a bilingual (2L1) Norwegian-Russian context. We investigate how previous knowledge of two typologically distant languages, Norwegian and Russian, can affect the L3A of a language which shows certain structural similarities with both previously acquired languages. The behavior of Norwegian-Russian bilinguals is compared to that of age-matched Norwegian and Russian L2 learners of English. The results of the study show that despite the typological similarity between Norwegian and English, the behavior of the bilinguals differs significantly from that of the 
monolinguals, suggesting CLI from both previously learned languages. The results and their implications are discussed in light of the LPM and previous models of L3A.

\section{Theoretical underpinnings of L3A}

Previous hypotheses and empirical evidence

Order of acquisition: One of the possible scenarios in L3A is transfer from the L1, indicating that the learner's native language is the main source of influence. No model of absolute L1 transfer in L3A has been proposed, yet several studies have found evidence of L1 influence (Lozano, 2003; Jin, 2009; Na Ranong \& Leung, 2009; Hermas, 2014). For example, Hermas (2014) finds that L1 Arabic is the source of both facilitative and nonfacilitative transfer for advanced L2 French adults in the initial stages of L3 English (in two different constructions). Furthermore, Jin (2009) observes a non-facilitative effect of L1 Chinese on L3 Norwegian, despite the presence of an advanced L2 English grammar which instantiates the target feature. Other studies find influence from the L2, which has led to the L2 Status Factor model, according to which the L2 is a privileged source of transfer, especially at early stages (Bardel \& Falk, 2007, 2012). This model is supported by experimental evidence suggesting that implicit linguistic competence and explicit 
metalinguistic knowledge are neurolinguistically distinct and have different memory sources (Paradis, 2004, 2009), the former being sustained by procedural memory and the latter by declarative memory (Ullmann, 2001). Thus, while an L1 grammar is implicitly acquired and sustained by procedural memory, an L2 grammar is typically based on explicit knowledge and sustained by declarative memory. And since an L3 grammar is learned in the same way as an L2 grammar, transfer will occur between the two languages that are both stored in declarative memory. Evidence for the L2 Status Factor has generally been found in studies of English and other Germanic languages, typically focusing on word order phenomena (Bardel \& Falk, 2007; Falk \& Bardel, 2011).

The Cumulative Enhancement Model: In contrast to the L2 Status Factor, the Cumulative Enhancement Model (CEM) argues that L3 syntactic transfer is selective and comes from either the L1 or the L2, cf. Flynn et al. (2004). According to the CEM, language acquisition is gradual and cumulative, and any prior language can either enhance subsequent language acquisition or have no effect. This means that non-facilitative transfer should not occur. Evidence for this model comes from a study examining the production of restrictive relative clauses in L1 Kazakh / L2 Russian / L3 English, where L3 English matches L2 Russian, but not L1 Kazakh. These learners are compared to L1 Japanese and L1 Spanish learners of L2 
English, the former language patterning with Kazakh and the latter with Russian with respect to the relevant structure. The results reveal transfer from L1 Spanish for the L2 learners and from L2 Russian for the trilinguals, in both cases providing facilitating influence.

Typology-based models: There is a long tradition in L3A arguing for a privileged role of typological proximity for CLI (cf. the overview in De Angelis, 2007). While many of these studies have been concerned with the acquisition of the lexicon (see e.g. Cenoz, 2003), Leung $(1998,2003)$ extends this idea to the domain of morphosyntax, proposing what is referred to as the Interlanguage Transfer Hypothesis (ITH; a term due to Jin, 2009). The ITH invokes Kellerman's $(1979,1983)$ idea of psychotypology, i.e. the language learner's perception of the properties of the source and target languages as close vs. distant and core vs. non-core. According to this idea, transfer is predicted to affect close and core properties. Furthermore, referring to the Full Transfer Full Access hypothesis of Schwartz \& Sprouse (1996), Leung proposed the idea of full transfer at the initial state of L3A from the most (psycho)typologically close language. The ITH thus argues that 'the Ln initial state is the steady state of a previously acquired (inter)language which is typologically closest to Ln' (Leung 2003: 199). 
A number of subsequent studies have tested the effect of typology in a variety of L3 populations. For example, Foote (2009) focuses on the role of typology in L3 transfer and disentangles the two predictors, L2 status and typology, by comparing the acquisition of the contrast in aspectual meaning in Romance past tenses in three groups of learners, L1 English / L2 Romance / L3 Romance, L1 Romance / L2 English / L3 Romance, and L1 English / L2 Romance, with a mean exposure to the L2 of 12 years and to the L3 of 5 years. The results of the study support the ITH, showing that language typology is the principal predictor for CLI.

Rothman (2011) proposes the same basic hypothesis (wholesale initial transfer from the typologically closest language), referring to it as the Typological Primacy Model (TPM). Rothman $(2013,2015)$ elaborates on the mechanisms that allow the parser to evaluate typological/structural proximity, suggesting that the choice of the source of transfer is based on similarity in lexicon, phonology, morphology and, finally, surface syntactic structures (Rothman, 2013:7). This list is meant to be implicationally hierarchical, representing cues that are more available or salient to the parser early in the L3 process. It is argued that after conducting the comparison, the parser chooses which of the two languages is typologically/structurally closer to the L3 and then transfers the complete grammar of this language to the L3 in one fell swoop. 
Another important notion introduced by Rothman is that of initial stages. Since the choice of the transfer source depends on the comparison between certain structural properties of the L3 and the two previously learned languages, transfer cannot occur at the initial state, before any exposure to the L3. Instead, the learner needs to have some basic experience with the L3 before the parser can make the decision. This short period of time is referred to as the initial stages in Rothman $(2011,2013,2015)$. However, it is not clear how the initial stages should be identified in terms of extent of exposure, and according to Gonzales Alonso \& Rothman (this issue), this would not even be a fruitful endeavor. Instead, the initial stages are argued to be 'the period in which structurally driven wholesale transfer from the L1 or the L2 takes place' (Gonzales Alonso \& Rothman, this issue). Thus, the TPM argues for a special status of the initial stages, and in fact, unlike all other models that we are aware of, the TPM does not make predictions for later stages of L3A (except developmental stages that derive directly from the initial stages, cf. Gonzales Alonso \& Rothman, this issue).

Evidence in support of the TPM is primarily based on experiments carried out during the first months or weeks of instruction, typically with speakers of English and a Romance language learning another Romance language as an L3, e.g. Rothman \& Cabrelli Amaro (2010). These studies consistently show that the L3 learners transfer from the previously 
learned Romance language (either the L1 or the L2), even in cases where this leads to a non-target-consistent result and transferring from English would have been facilitative. Support for the TPM is also found in studies investigating L3 acquisition by simultaneous bilinguals, comparing them to successive bilinguals (Iverson, 2009; Giancaspro, Halloran \& Iverson, 2015). Both studies test the acquisition of L3 Brazilian Portuguese by L1/L2/2L1 speakers of English and Spanish. Based on data from the acquisition of gender agreement, noun drop and direct object marking, these studies reveal transfer from Spanish, irrespective of its status as L1, L2 or bilingual first language. We return to the TPM and the role of typological similarity at early stages of L3A in the discussion section.

The Linguistic Proximity Model: The most problematic issue for typology-based models is the reported existence of CLI from the typologically more distant language, e.g. Jin (2009) showing influence from L1 Chinese (instead of L2 English) into L3 Norwegian, or Hermas (2014), showing influence from L1 Arabic (instead of L2 French) into L3 English. The CEM, on the other hand, cannot explain findings of non-facilitative influence in L3A, e.g. Rothman \& Cabrelli Amaro (2010), showing transfer from L2 Spanish into L3 French for the null subject property. In this section, we propose a new model of L3 acquisition that argues for CLI from both previously learned languages, the Linguistic Proximity Model 
(LPM). In the next section, we also provide new empirical evidence from a study designed to test the predictions of the CEM, Typology-based models, and the LPM.

The LPM builds on what we consider to be the positive aspects of the CEM and the TPM, viz. that certain similarities between the three languages play a major role, not the order of acquisition. However, instead of arguing that general typological proximity is the decisive factor, we claim that similarity of abstract linguistic properties is the main cause of CLI from previously learned languages. The model allows for both facilitative and nonfacilitative influence. Furthermore, based on recent evidence that the languages of a multilingual individual are not completely separate (see Slabakova, this issue), we contend that all previously learned languages are available throughout the L3 learning process. Much current work on executive control in bilinguals (e.g. Bialystok, 2011) also shows that the language not in use remains active and must typically be inhibited when speaking the other language. Our approach is also in line with much early work on crosslinguistic influence, cf. the notion combined CLI in De Angelis (2007: 21), which refers to a situation where 'two or more languages interact with one another and concur in influencing the target language.' Thus, we formulate the LPM as follows: 
Linguistic Proximity Model: Ln acquisition involves incremental property-by-property learning and allows for both facilitative and non-facilitative influence from one or both previously acquired languages. Crosslinguistic influence occurs when a particular linguistic property in the $\mathrm{L} n$ input reveals abstract structural similarity with linguistic properties of the previously learned languages.

This means that bilinguals learning an L3 (whether they have two first languages or an L1 plus L2) should benefit from both of the languages they know. Conversely, they may also experience non-facilitative influence from either language. Furthermore, the LPM predicts different learning patterns for different linguistic phenomena. The source of CLI with respect to a particular property is based on structural similarities between the L3 and one (or both) of the previously acquired languages, rather than overall typological proximity between one of them and the L3. Obviously, this kind of CLI may take place only if the learner is able to parse the $\mathrm{L} n$ input and identify abstract linguistic properties.

Unlike typology-based models, the LPM does not assume the idea of complete transfer of one of the previously acquired grammars early on in L3A, excluding any influence from the other language at this stage. In our view, some clear empirical evidence would be needed to justify such a process, but as far as we are aware, no such evidence has been 
provided. Rothman (2015: 184) motivates wholesale transfer at the initial stages of L3A in terms of cognitive economy and argues that 'if transfer is essentially reflexive to avoid redundancy in acquisition and thereby lessen the cognitive burden of an additional grammar, it should then obtain as early and completely as possible to be maximally useful towards these fundamental goals'. However, the notion of economy is purely conceptual, and in our view, one could also propose a view of economy which would favor incremental learning. For example, it might be argued to be more economical to have a wait-and-see approach to language transfer, performing it on a small part of grammar when and where there is sufficient evidence indicating that this is a relevant move. This would reduce the amount of effort required to unlearn incorrectly transferred properties.

Thus, the LPM argues that all previously learned languages remain active and that learners are sensitive to micro-variation across all three grammars. In this way, the LPM is compatible with the micro-cue model of Westergaard $(2009,2014)$ for first language acquisition, which argues that young children are able to make fine distinctions in syntax and information structure from early on. This model is currently being extended to multilingual contexts, the main hypothesis being that only small and simple rules may transfer (cf. Amaral \& Roeper, 2014). This is also in agreement with the Scalpel model (Slabakova, this issue), which considers the language acquisition capacity (for the L1 as 
well as subsequently acquired languages) to be a sharp instrument, capable of making clear and fine distinctions. Summarizing, the LPM argues for the following:

- In the course of L3A, learners have access to all previously acquired linguistic knowledge. Acquisition is cumulative, and no part of previous linguistic competence is blocked at any stage of the process.

- CLI occurs property-by-property, based on similarity or overlap between the grammars, not necessarily identity.

- Facilitative influence is based on structural similarity: Learners parse L3 input and make predictions by consulting previously acquired grammars.

- Non-facilitative influence occurs when learners misanalyse L3 input (and/or have not had sufficient L3 input), and mistakenly assume that a property is shared between the L3 and either or both of the previously acquired languages.

\section{Our study}

Research questions and predictions 
The present study investigates crosslinguistic effects in the acquisition of L3 English by 2L1 Norwegian-Russian speakers as compared to monolingual Norwegian (L1Nor) and monolingual Russian (L1Rus) controls. While Norwegian and English are both Germanic languages that are lexically and structurally close, Russian, being a Slavic language, is more distant from English both with respect to vocabulary and morphosyntax.

The linguistic phenomena we consider are related to verb-second (V2) word order in Norwegian and the corresponding residual V2 property of English, generally referred to as subject-auxiliary inversion. According to standard accounts of V2 (e.g. Vikner, 1995), this word order is the result of finite verb movement to the second position of the clause, most often assumed to be the $\mathrm{C}$ (omplementizer) position or some other head in the left periphery (cf. e.g. Westergaard, 2008). While earlier versions of English had certain V2 properties, this word order has generally been lost in declaratives and only survives as a rule inverting subjects and auxiliaries in questions (cf. e.g. Roberts, 1996; Westergaard, 2007). This means that present-day English has non-V2 in declaratives and is thus like Russian in this respect, with finite verbs appearing below sentence adverbs (Adv-V). ${ }^{1}$ Norwegian displays V-Adv word order, due to verb movement across the adverb to second position. The word order of wh-questions, on the other hand, highlights structural similarity between English

\footnotetext{
${ }^{1}$ Russian is characterized by flexible word order, yet there is a strong preference for Adv-V in declaratives among native speakers (a score of 4.8-4.9 out of 5, according to Kallestinova \& Slabakova, 2008).
} 
and Norwegian as opposed to Russian. Specifically, English and Norwegian exhibit inversion of the subject and the finite verb (auxiliary), while Russian generally does not. ${ }^{2}$ The differences between the three languages are illustrated in (1)-(2).

(1) Adverb-Verb word order (no V2)

ENG $=$ RUS $\neq$ NOR

\begin{tabular}{|c|c|c|c|}
\hline Emma & often & eats & sweets. \\
\hline Emma & často & jest & konfety. \\
\hline Emma & ofte & & konfekt. \\
\hline
\end{tabular}

(2) Subject-Auxiliary inversion (residual V2)

ENG $=$ NOR $\neq$ RUS

\begin{tabular}{|c|c|c|c|}
\hline What & will & the little girl & read? \\
\hline Hva & vil & den lille jenta & lese? \\
\hline to & & eta malen'kaja devočka & budet čitat'? \\
\hline
\end{tabular}

\footnotetext{
${ }^{2}$ It should be noted that Russian marginally allows Aux-S word order, but this is pragmatically marked compared to the default S-Aux-V word order.
} 
Previous investigation of these constructions in L2 English is discussed in Westergaard (2003), based on data from L1 Norwegian 12-13-year-olds ( $6^{\text {th }}$ and $7^{\text {th }}$ graders), who had been exposed to English in a classroom setting from the age of 6 . The Adv-V word order was found to be quite problematic for these learners, who regularly transferred verb movement from Norwegian (only $17 \%$ accuracy in $6^{\text {th }}$ grade, increasing to $58 \%$ in $7^{\text {th }}$ grade). At the same time, these learners showed target-like performance with subjectauxiliary inversion in questions ( $93 \%$ and $92 \%$ in $6^{\text {th }}$ and $7^{\text {th }}$ grade respectively). We are not aware of previous studies investigating L2 acquisition of these word order phenomena by L1 Russians.

We address the following research questions:

A. Do both languages contribute to CLI in L3 acquisition, or is one of them chosen as the sole source of influence?

B. Is CLI always from the typologically more similar language?

C. Is CLI always facilitative, or can it be non-facilitative as well? 
In light of the LPM, we predict CLI to occur from both previously acquired languages. More specifically, the model makes the following predictions: ${ }^{3}$

\section{Adv placement (Adv-V)}

- Monolingual Russians (L1Rus) are predicted to perform at ceiling, due to word order similarity between their L1 and L2.

- Monolingual Norwegians (L1Nor) are expected to transfer verb movement, due to influence from the V2 property.

- Bilinguals (2L1) are predicted to outperform L1Nor, due to access to Russian. However, they may score lower than L1Rus, due to non-facilitative influence from Norwegian.

\section{S-Aux inversion (Aux-S)}

- L1Nor are predicted to perform at ceiling, due to facilitative transfer of verb movement.

- L1Rus are expected to have difficulties, due to non-facilitative influence from Russian.

- $2 \mathrm{~L} 1$ are predicted to outperform L1Rus, due to access to Norwegian. However, they may score lower than L1Nor, due to non-facilitative influence from Russian.

\footnotetext{
${ }^{3}$ While the conditions are referred to here as Adv-V and Aux-S for simplicity, we are assuming that what is transferred is not superficial word order, but rather the process of verb movement.
} 
Let us now consider the predictions of the CEM and Typology-based models with respect to the current study. According to the CEM, bilinguals should benefit from both languages, and non-facilitative influence should not occur. In other words, Norwegian-Russian bilinguals are expected to perform on a par with L1 Russians in the first condition (Adv-V) and with L1 Norwegians in the second condition (Aux-S). On the other hand, Typologybased Models predict that 2L1 bilinguals would pattern with L1 Norwegians on both conditions, since Norwegian is typologically closer to English than Russian. The predictions of the LPM, the CEM and Typology-based Models (referred to as TM here) are summarized in Table $1 .^{4}$

\footnotetext{
${ }^{4}$ Since the TPM (Rothman, 2011, 2015) claims to make predictions only about the initial stages, it is unclear whether this model could be subsumed under Typology-based Models here.
} 
Table 1. Summary of predictions

\begin{tabular}{lllllll}
\hline Prior & CEM & & & & TMM & \\
language & & & & & \\
know- & & Adv-V & Adv-V & Aux-S & Adv-V & Aux-S \\
ledge & & & & & & \\
\hline 2L1 & Facilitative & Facilitative & Non- & Facilitative & Facilitative & Facilitative \\
NOR- & effect from & effect from & facilitative & effect from & effect from & effect from \\
RUS & RUS & NOR & effect from & NOR & RUS & NOR \\
& & & NOR & & & \\
\hline 2L1 vs. & Bilingual & Equivalence & Equivalence & Equivalence & Bilingual & Bilingual \\
L1Nor & advantage & & & & advantage & disadvantage \\
\hline 2L1 vs. & Equivalence & Bilingual & Bilingual & Bilingual & Bilingual & Bilingual \\
L1Rus & & advantage & disadvantage & advantage & disadvantage & advantage \\
\hline
\end{tabular}

\section{Participants}

We recruited 110 secondary school students in $6^{\text {th }}$ and $7^{\text {th }}$ grade, age range $11-14$. The participants belonged to three groups: Norwegian-Russian bilinguals $(N=22)$, Norwegianspeaking monolinguals ( $N=46)$, and Russian-speaking monolinguals $(N=31)$; see Table 2 . The Norwegian-Russian bilinguals and the Norwegian monolinguals were recruited in Norway (Tromsø and Oslo), while the Russian monolinguals lived in Russia (Moscow). All 
the children had studied English since grade 1 (age 6). The 2L1 children attended the same public schools as the monolingual Norwegians and had received exactly the same exposure to English. The participants were selected from a larger pool based on the results of a short vocabulary test, consisting of a subset of the BPVS-II (1997). Only children who scored $60 \%$ or more were included in the dataset.

Table 2. Participants' demographics and vocabulary scores (VS)

\begin{tabular}{lcccc}
\hline Group & Number & Mean age (SD) & Age range & Mean VS (SD) \\
\hline 2L1Nor-Rus & 22 & $12.5(1.2)$ & $11-14$ & $8.7(1.17)$ \\
L1Nor & 46 & $12.0(0.7)$ & $11-13$ & $8.7(1.42)$ \\
L1Rus & 31 & $12.0(0.6)$ & $11-13$ & $7.8(1.19)$ \\
\hline
\end{tabular}

\section{Materials and procedure}

We conducted a Grammaticality Judgment Task with two conditions, declaratives with adverbs and questions with auxiliaries, illustrated in Table 3. Each condition included 12

\footnotetext{
${ }^{5}$ Fourteen of the bilingual children were born in Norway: ten in families with one Russian- and one Norwegian-speaking parent and four in families with two Russian-speaking parents. The remaining eight bilinguals arrived in Norway before age 5; four lived in Norwegian-Russian families and four in families with two Russian-speaking parents.
} 
test sentences, six grammatical and six ungrammatical; see examples (3)-(4). The stimuli further involved 24 filler sentences with both grammatical and ungrammatical word order.

Table 3. Experimental conditions

\begin{tabular}{lll}
\hline Structure & Condition 1: & Condition 2: \\
& Declaratives with Adverbs & Questions with Auxiliaries \\
\hline Grammatical & $\mathrm{S}_{\mathrm{NP}}$ Adv V O $_{\mathrm{NP}}$ & Wh Aux S $\mathrm{NP} \mathrm{V} ?$ \\
Ungrammatical & $* \mathrm{~S}_{\mathrm{NP}} \mathrm{V} \mathrm{Adv} \mathrm{O}_{\mathrm{NP}}$ & $* \mathrm{Wh} \mathrm{S}_{\mathrm{NP}}$ Aux V? \\
\hline
\end{tabular}

(3) a. Susan often eats sweets.

b. *Susan eats often sweets.

(4) a. What will the little girl read?

b. *What the little girl will read?

The 48 experimental items were randomized and presented as a power point presentation, which was timed and involved both visual and audio stimuli (see Appendix 1). A native speaker of American English pre-recorded the sentences with a natural declarative or 
interrogative prosodic contour. The children heard each sentence once and had to mark it as either grammatical or ungrammatical on a scoring sheet. The presentation was preceded by a training session. The bilingual children were tested in small groups or individually, while the monolinguals were tested in classrooms in larger groups. ${ }^{6}$ All children received exactly the same stimuli regardless of the type of setting.

\section{Results}

Overall results

The overall correctness scores for the two conditions are illustrated in Figure 1.

\footnotetext{
${ }^{6}$ Bilinguals who attended Russian language classes were tested in small groups; others were tested
} individually. 


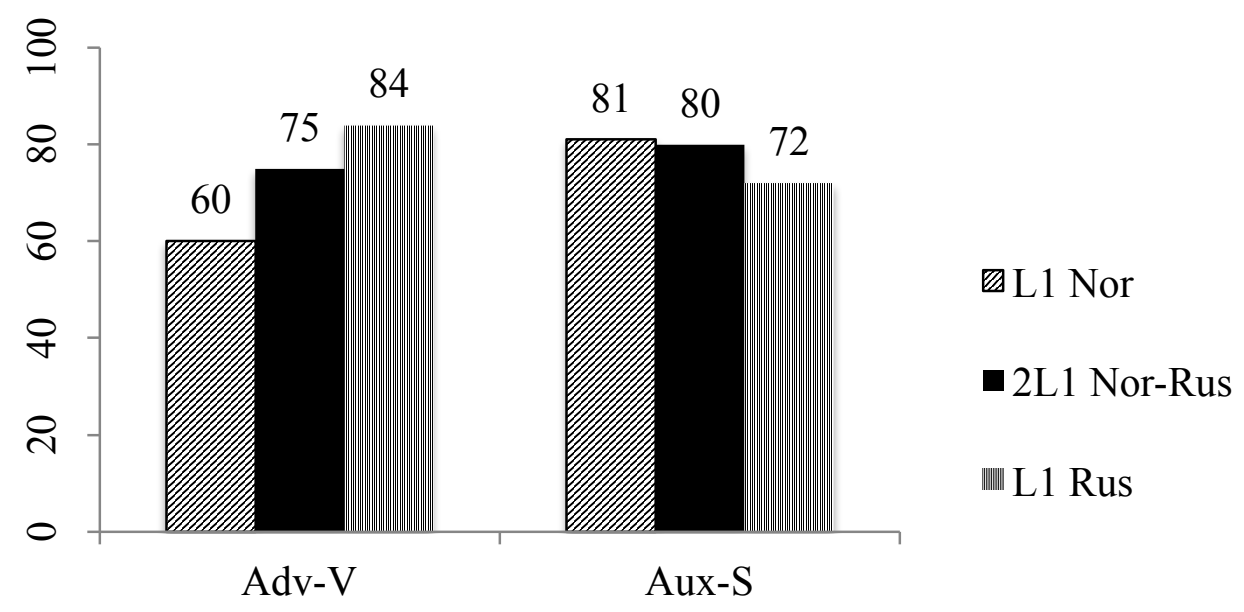

Figure 1. Percentage of correct responses in two conditions: Adv-V and Aux-S.

We fitted a generalized linear mixed effects logistic regression (cf. Jaeger, 2008; Quené \& van der Bergh, 2008) to estimate the effects of CONDITION $(A d v-V, A u x-S)$, LANGUAGE (Norwegian, Norwegian-Russian, Russian) and their interaction on the CORRECTNESS OF JUDGMENTS ( 1 if the sentence was judged correctly, 0 otherwise). We included random byparticipant and by-item intercepts, as well as participant-by-condition and item-by-language random slopes. The analysis was conducted using the library lme4 (Bates, Maechler, Bolker \& Walker, 2014) of the statistics software R version 3.1.2 (release 2014-10-31). After fitting an omnibus model with two categorical predictors and their interaction, we conducted simultaneous multiple comparisons of different levels of the variables in 
addition to those that were already established in the output of the omnibus model. ${ }^{7}$ Group comparisons for each condition were calculated using post-hoc tests with the help of the multcomp package (Hothorn, Bretz \& Westfall, 2008). The details of the statistical analysis are provided in Appendix 2, Tables 5-8.

The results showed a significant main effect of LANGUAGE in the Adv-V condition: Both the L1Rus group and the 2L1Nor-Rus group performed significantly better than the L1Nor group $(B=1.47, S E=0.32, Z=4.57, p<.001$ and $B=0.84, S E=0.32, Z=2.68, p<$ .05 , respectively). In the Aux-S condition, LANGUAGE was not a significant predictor of accuracy; see more in Appendix 2, Table 5. As illustrated in Figure 1, the overall scores are high both for bilinguals and L1 Norwegians ( $80 \%$ and $81 \%$ respectively). L1 Russian children scored slightly lower (72\%), but this difference is not significant.

\section{Grammatical vs. ungrammatical sentences}

In addition to the omnibus model, we fitted two generalized linear mixed-effects models where grammatical and ungrammatical sentences were analyzed separately (the predictors

\footnotetext{
${ }^{7}$ In order to exclude the possibility that the participants' answers on grammatical and ungrammatical sentences were not correlated within individual conditions, we additionally fit a generalized linear mixed effects model where RAW JUDGMENTS ( 1 for grammatical and 0 for ungrammatical judgments) were modeled by GRAMMATICALITY and CONDITION as predictors. Participants and items were included as random effects. The effect of grammaticality was highly significant $\left(p<2 \mathrm{e}-16^{* * *}\right)$, showing that the participants' answers on grammatical and ungrammatical trials within conditions were correlated.
} 
were the same as in the omnibus model: LANGUAGE and CONDITION as well as their interaction). Maximal random effects were included. We used the multicomp package (Hothorn et al., 2008) for the post-hoc multiple comparisons. The outputs of the two models are presented in the Appendix (Tables 6 and 7), and the output of the multiple comparisons tests are summarized in Table 8 of the Appendix.

We first consider adverb placement/verb movement in declaratives. As illustrated in Figure 2, when presented with grammatical Adv-V sentences (e.g. Emma often eats sweets), the L1 Russian children scored significantly higher than the L1 Norwegians: $83 \%$ vs. $55 \%,(B=1.69, S E=0.46, Z=3.65, p<.01)$. The $2 \mathrm{~L} 1$ children scored higher than the L1 Norwegians, but lower than the L1 Russians (65\%). There is a marginally significant difference between the L1Rus and the 2L1 children $(B=1.17, S E=0.48, Z=2.48, p=$ 0.07). The difference between the L1Nor and the bilingual children is not significant.

For ungrammatical trials (e.g. *Emma eats often sweets), the accuracy rates of the 2L1 children matched those of the L1Rus participants ( $84 \%$ vs. $85 \%$ ). Both groups scored significantly higher than the L1Nor group, $84 \%$ vs. $65 \%(B=1.27, S E=0.43, Z=2.96, p<$ 
$.05)$ and $85 \%$ vs. $65 \%(B=1.33, S E=0.36, Z=3.66, p<.01)$, while the difference between the L1Rus and 2L1 children is not significant (cf. Table 8 in Appendix 2) ${ }^{8}$.

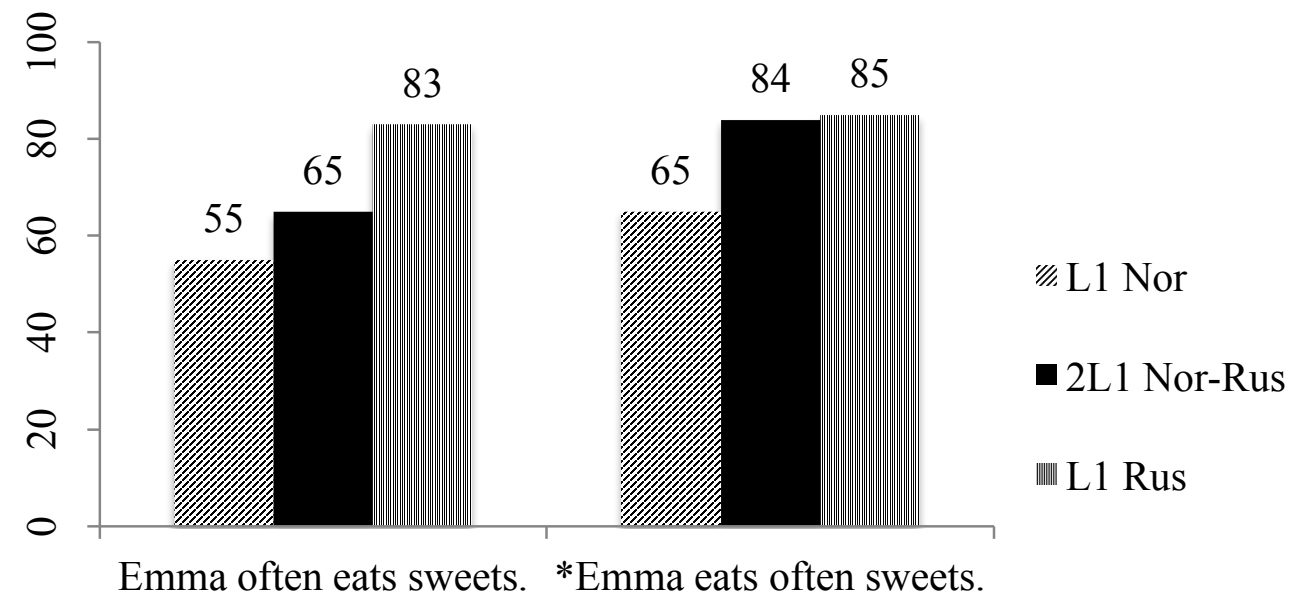

Figure 2. Percentage of correct responses in grammatical (Adv-V) and ungrammatical (VAdv) sentences.

\footnotetext{
${ }^{8}$ To exclude potential yes- or no-biases, we checked if there were any significant differences in the correctness of judgments between the grammatical and ungrammatical sentences in an additional omnibus model. However, the effect of GRAMMATICALITY as well as the interaction of GRAMMATICALITY and LANGUAGE were not significant, which indicates that none of the groups had a significant yes- or no-bias. Consequently, the performance of the bilingual group on ungrammatical trials in the Adverb condition cannot be attributed to an overall no-bias in this group.
} 
We then consider subject-auxiliary inversion. Recall that the omnibus model didn't reveal any significant differences between the groups in this condition. The additional models confirmed this result. As illustrated in Figure 3, all groups had high scores in the ungrammatical trials (78\%-80\%). In grammatical sentences, the L1Rus participants scored slightly lower (67\%), but the contrasts between the groups are not significant (cf. Appendix 2, Table 8).

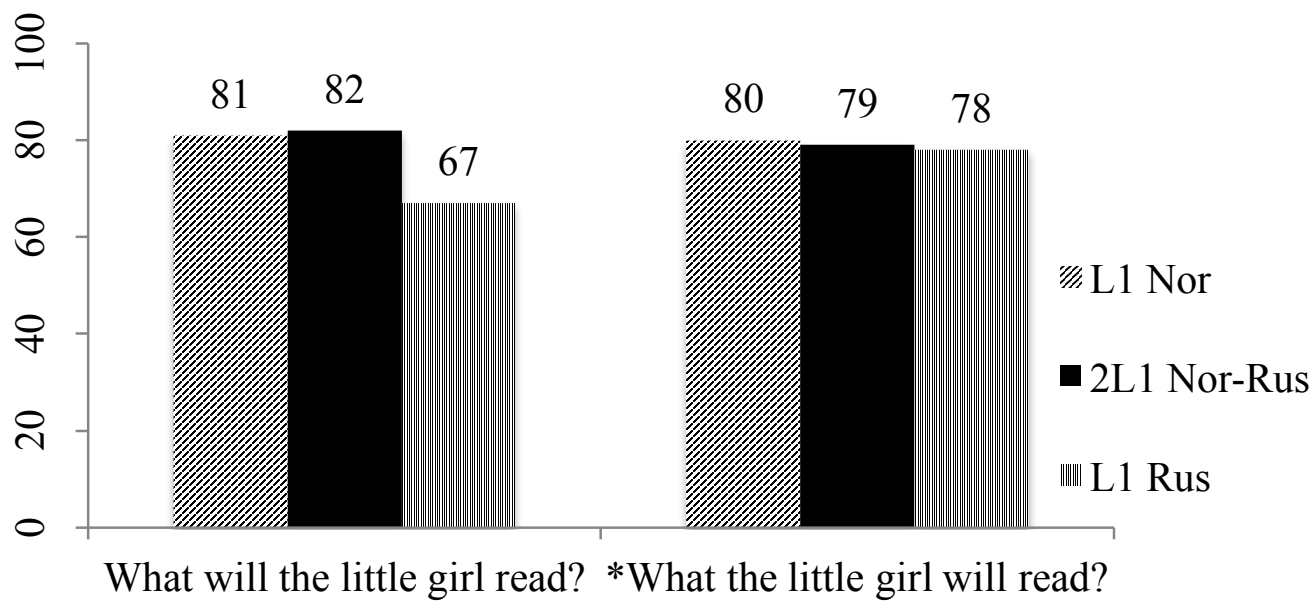

Figure 3. Percentage of correct responses in grammatical (Aux-S) and ungrammatical (SAux) sentences. 
To sum up, the analysis revealed significant differences between the three groups of participants in Condition $1(\mathrm{Adv}-\mathrm{V})$. Monolingual Russians performed significantly better than monolingual Norwegians overall and on grammatical and ungrammatical trials examined separately. Bilinguals scored significantly higher than monolingual Norwegians overall and in particular with respect to the judgment of ungrammatical sentences. On grammatical trials, their performance was not significantly different from that of monolingual Norwegians. There was no significant difference between the bilinguals and the monolingual Russians overall and on the judgment of ungrammatical sentences. However, there was a marginally significant difference between these two groups on the grammatical sentences (bilinguals scored lower). In Condition 2 (Aux-S) no significant differences were observed between the three groups of participants. All three groups performed at ceiling overall and in grammatical and ungrammatical trials examined separately.

\section{Discussion}

Our experimental data suggest that the Norwegian-Russian bilinguals experienced a significant facilitating effect of Russian in their L3 English, although Russian belongs to a different typological group than English and Norwegian. This effect is all the more 
remarkable given that Russian is the minority language for the bilinguals in this study. Let us consider this result in some more detail in relation to the predictions we formulated based on the LPM (repeated here for convenience):

\section{Adv placement (Adv-V)}

- L1Rus are predicted to perform at ceiling, due to word order similarity between their L1 and L2.

- L1Nor are expected to transfer verb movement, due to influence from the V2 property.

- $2 \mathrm{~L} 1$ are predicted to outperform L1Nor, due to access to Russian. However, they may score lower than L1Rus, due to non-facilitative influence from Norwegian.

\section{S-Aux inversion (Aux-S)}

- L1Nor are predicted to perform at ceiling, due to facilitative transfer of verb movement.

- L1Rus are expected to have difficulties, due to non-facilitative influence from Russian.

- $2 \mathrm{~L} 1$ are predicted to outperform L1Rus, due to access to Norwegian. However, they may score lower than L1Nor, due to non-facilitative influence from Russian. 
The results from the acquisition of $\mathrm{Adv}-\mathrm{V}$ word order in declaratives indicate a significant facilitative influence of Russian: high accuracy rates for L1Rus children as well as the bilinguals, both groups outperforming L1 Norwegians (Figure 1). The fact that L1 Norwegians score significantly lower than the L1 Russians suggests that these learners transfer verb movement (V2) from their L1 Norwegian. The score of the bilinguals is in between the two control groups, suggesting both facilitative and non-facilitative influence (from Russian and Norwegian respectively). At the same time, further evidence from the 2L1 learners' judgment of grammatical and ungrammatical sentences reveals an interesting contrast: While their judgment of ungrammatical sentences is nearly target-like and significantly better than that of L1Nor ( $84 \%$ vs. $65 \%$ respectively), their judgment of grammatical structures is significantly lower than that of the L1Rus group and reaches only $65 \%$ accuracy (Figure 2). This indicates that a non-facilitative effect of Norwegian is present at this developmental stage for the $2 \mathrm{~L} 1$ participants. Thus, all our predictions for Condition 1 are borne out.

For subject-auxiliary inversion, the bilinguals as well as the L1Nor speakers have high scores ( $80 \%$ and $81 \%)$, and while the L1 Russians, as expected, score somewhat lower (72\%), this difference is not significant (Figure 1). The fact that we did not find bilinguals outperforming L1 Russians on inversion (as we predicted) might be attributed to the 
proficiency level of the participants. That is, the learners seem to have already acquired subject-auxiliary inversion in English, and any non-facilitative effect of Russian is no longer present. Disappointing as that may be (for our model), the fact that a property of the L3 has already been learned does not constitute a problem for the LPM (or any other model, for that matter).

Our findings have a number of implications for theories of L3A. First, we do not find support for Typology-based models, since there is strong evidence of a facilitating effect of Adv-V word order from Russian. Thus, the typological proximity between Norwegian and English was overridden by facilitative CLI from Russian, which exhibits structural similarity with English in this condition. Second, with respect to the CEM, we do find a facilitating effect of one of the languages, in that the $2 \mathrm{~L} 1$ children clearly benefit from Russian. However, non-facilitative influence from Norwegian can be detected in the judgment of grammatical sentences, which goes against the predictions of the CEM.

The results of our study are consistent with the LPM, which assumes combined CLI of the previously learned languages on L3A and allows for both facilitative and nonfacilitative effects. However, one part of our results remains unaccounted for, namely the observed contrast between the judgments of grammatical and ungrammatical sentences by the bilinguals, who tended to reject both the ungrammatical and the grammatical sentences 
in English (Adv-V and V-Adv). We would like to speculate that this could be due to what we may refer to as the 'double filter effect': Let us assume that all speakers have a grammaticality filter that is activated in cases where one has to process and judge linguistic data; L2 learners will have a single filter and L3 learners a double filter. A sentence is analyzed by a speaker's grammar before a judgment about its grammaticality is made. In the case of bilingual speakers, at a stage when the L3 interlanguage is still unstable, the grammars of both previously acquired languages will be consulted. Thus, each sentence presented to an L3 learner must pass the filter of both previously acquired grammars in order to be judged as grammatical. In the case of adverb placement, the bilinguals would have received intuitions from their Norwegian grammar that Adv-V word order is ungrammatical, and thus incorrectly rejected a high number of such sentences. At the same time, they would have received intuitions about the ill-formedness of V-Adv from their Russian grammar and again overwhelmingly rejected them. Thus, the double filter resulted in bilingual participants to a large extent rejecting both grammatical and ungrammatical sentences and thus being right more often with ungrammatical ones. Such an effect should not occur in L2 acquisition, where learners have only one previously acquired language and thus a single filter. At this point we do not have empirical data to further specify the 
mechanisms underlying the double-filter effect, and we must leave this issue for future research.

Another relevant issue is the learners' proficiency in the L3. As mentioned above, it is evident that similarity at an abstract structural level can only be established in the presence of sufficient exposure and subsequent ability to parse the L3 input. Until such exposure is obtained, we find it likely that learners may rely on more superficial heuristics, e.g. comparison at the lexical or phonological levels (cf. Rothman, 2013). Thus, in a situation where one of the previously learned languages bears close surface resemblance to the L3, we may see substantially more influence from that language at the earliest stages of acquisition. This may account for the results reported by Rothman \& Cabrelli Amaro (2010); Iverson (2009), etc. We expect that as exposure to the L3 grows, the role of overall typological proximity should decrease, while the role of more abstract structural similarities should increase.

To sum up, the results of our study support the hypothesis that both previously learned languages remain active and influence subsequent L3 acquisition. Furthermore, they suggest that CLI can be both facilitative and non-facilitative. We have argued that the crucial factor in establishing the direction of CLI is linguistic proximity at an abstract level. We acknowledge that superficial heuristics may play a role at the earliest stages of L3A 
when the learner has not yet obtained sufficient input from the L3 to discern similarities at a more abstract level. Nevertheless, we maintain that as the exposure to an L3 grows, CLI should become more dependent on abstract structural proximity.

\section{Conclusion}

This paper argues for a new model of L3A, the Linguistic Proximity Model (LPM), according to which CLI occurs when a certain linguistic property receives supporting evidence from one or both of the previously acquired languages, regardless of the order of acquisition or general typological grouping. According to the LPM, all previously acquired languages remain active throughout the learning process, and CLI takes place on a property-by property basis. Furthermore, this influence may be both facilitative and nonfacilitative. The model has been tested in a bilingual setting, 2L1 Norwegian-Russian / L3 English, focusing on two word order phenomena related to verb movement: adverb placement in declaratives and subject-auxiliary inversion in questions. With respect to the first property, English patterns with Russian (Adv-V), while English is similar to Norwegian with respect to the second property (Aux-S). Our hypothesis is supported by the results of a Grammaticality Judgment Task: While L1 Norwegian children over-accept ungrammatical sentences in English with a word order that is equivalent to Norwegian V2 
(V-Adv), bilingual Norwegian-Russian children notice these errors significantly more often, which we argue is due to facilitating influence of Russian. At the same time, the bilinguals score lower than L1 Russian children on grammatical trials, suggesting the presence of non-facilitative influence from Norwegian. Thus, we conclude that the results of our study can be better captured by the LPM than by other existing models. Our findings indicate that not just typological proximity but also structural similarity at an abstract level should be considered an important factor in L3A.

\section{References}

Amaral, L., \& Roeper, T. (2014). Multiple Grammars and Second Language Representation. Second Language Research, 30(1), 3-36.

De Angelis, G. (2007). Third or Additional Language Acquisition. Clevedon: Multilingual Matters.

Bardel, C., \& Falk, Y. (2007). The role of the second language in third language acquisition: The case of Germanic syntax. Second Language Research, 23, 459-484. 
Bardel, C., \& Falk, Y. (2012). Behind the L2 Status Factor: A neurolinguistic framework for L3 research. In J. Cabrelli Amaro, \& Rothman, J. (Ed.), Third language acquisition in adulthood (pp. 61-78). Amsterdam: John Benjamins.

Bates, D., Maechler, M., Bolker, B., \& Walker, S. (2014). Fitting Linear Mixed-Effects Models using lme4. ArXiv e-print; Journal of Statistical Software, http://arxiv.org/abs/1406.5823.

Berkes, É., \& Flynn, S. (2012). Further evidence in support of the CumulativeEnhancement Model: CP structure development. In J. Cabrelli Amaro, \& Rothman, J. (Ed.) Third language acquisition in adulthood (pp. 143-164). Amsterdam: John Benjamins.

Bialystok, E. (2011). Reshaping the mind: the benefits of bilingualism. Canadian Journal of Experimental Psychology, 65, 229-235.

British Picture Vocabulary Scale II (BPVS II). (1997). Windsor, Berks: NFER-Nelson.

Cenoz, J. (2003). The successive effect of bilingualism on third language acquisition: A review. International Journal of Bilingualism, 7(1), 71-87.

Falk, Y., \& Bardel, C. (2011). Object pronouns in German L3 syntax: Evidence for the L2 Status Factor. Second Language Research, 27, 59-82. 
Flynn, S., Foley, C., \& Vinnitskaya, I. (2004). The cumulative-enhancement model for language acquisition: Comparing adults' and children's patterns of development in first, second and third language acquisition of relative clauses. The International Journal of Multilingualism, 1, 3-16.

Foote, R. (2009). Transfer in L3 acquisition: The role of typology. In Y-K. I. Leung (Ed.), Third language acquisition and Universal Grammar (pp. 89-114). Clevedon: Multilingual Matters.

Giancaspro, D., Halloran, B., \& Iverson, M. (2015). Transfer at the initial stages of L3 Brazilian Portuguese: A look at three groups of English/Spanish bilinguals. Bilingualism: Language and Cognition, 18(2), 191-207.

Hermas, A. (2014). Multilingual transfer: L1 morphosyntax in L3 English. International Journal of Language Studies, 8(2), 10-24.

Hermas, A. (2015). The categorization of the relative complementizer phrase in thirdlanguage English: A feature re-assembly account. International Journal of Bilingualism, 19(5), 587-607.

Hothorn, T., Bretz, F., \& Westfall, P. (2008). Simultaneous Inference in General Parametric Models. Biometrical Journal, 50(3), 346-363. 
Iverson, M. (2009). N-drop at the initial state of L3 Portuguese: Comparing simultaneous and additive bilinguals of English/Spanish. In Pires, A., \& Rothman, J. (Ed.), Minimalist Inquiries into Child and Adult Language Acquisition: Case Studies Across Portuguese (pp. 221-244). Berlin/New York: Mouton DeGruyter.

Jaeger, T. F. (2008). Categorical data analysis: Away from ANOVAs (transformation or not) and towards Logit Mixed Models. Journal of Memory and Language, 59, 434-446.

Jin, F. (2009). Third language acquisition of Norwegian objects: Interlanguage transfer or L1 influence? In Y-k. I. Leung (Ed.), Third Language Acquisition and Universal Grammar (pp. 144-161). Bristol, UK: Multilingual Matters.

Kallestinova, E., \& Slabakova, R. (2008). Does the verb move in Russian? Proceedings of FASL 16, 199-214. Michigan Slavic Publications.

Kellerman, E. (1979). Transfer and non-transfer: Where we are now. Studies in second language acquisition 2.01, 37-57.

Kellerman, E. (1983). Now you see it, now you don't. In Gass, S. \& Selinker, L. (Ed.), Language Transfer in Language Learning, pp. 112-134. Rowley, MA: Newbury House. Leung, Y.-k. I., (1998). Transfer between interlanguages. Proceedings of the 22nd Boston University Conference on Language Development, pp. 477-487. Somerville, MA: Cascadilla Press. 
Leung 2003. Failed Features versus Full Transfer Full Access in the Acquisition of a Third Language: Evidence from Tense and Agreement. Proceedings of the 6 th generative approaches to a second language acquisition conference (GASLA 2002), pp. 199-207.

Lozano, C. (2003). Focus, pronouns and word order in the acquisition of L2 and L3 Spanish. Unpublished doctoral dissertation, University of Essex, UK.

Montrul, S., Dias, R., \& Santos, H. (2011). Clitics and object expression in the L3 acquisition of Brazilian Portuguese. Structural similarity matters for transfer. Special issue of Second Language Research on L3 acquisition, 27.1, 21-58.

Na Ranong, S., \& Leung, Y-k. I. (2009). Null objects in L1 Thai-L2 English-L3 Chinese: An empirical take on a theoretical problem. In Y-K. I. Leung (Ed.), Third Language Acquisition and Universal Grammar (pp. 162-191). Bristol, UK: Multilingual Matters.

Paradis, M. (2004). A Neurolinguistic Theory of Bilingualism. Amsterdam: John Benjamins.

Paradis, M. (2009). Declarative and Procedural Determinants of Second Languages. Amsterdam: John Benjamins.

Quené, H., \& van der Bergh, H. (2008). Examples of mixed effects modeling with crossed random effects and with binomial data. Journal of Memory and Language, 59, 413-425. 
Roberts, I. (1996). Remarks on the Old English C-system and the diachrony of V2. Linguistische Berichte, Sonderheft, 7, 154-168.

Rothman, J. (2011). L3 syntactic transfer selectivity and typological determinacy: The typological primacy model. Second Language Research, 27, 107-127.

Rothman, J. (2013). Cognitive economy, non-redundancy and typological primacy in L3 acquisition: Evidence from initial stages of L3 Romance. Romance languages and linguistic theory 2011 (pp. 217-247). Amsterdam: John Benjamins.

Rothman, J. (2015). Linguistic and cognitive motivations for the typological primacy model (TPM) of third language (L3) transfer: Timing of acquisition and proficiency considered. Bilingualism: Language and Cognition, 18(2), 179-190.

Rothman, J., \& Cabrelli Amaro, J. (2010). What variables condition syntactic transfer? A look at the L3 initial stage. Second Language Research, 23, 189-218.

Rothman, J., \& Gonzales Alonso, J. (this issue). Coming of age in L3 initial stages transfer models: Deriving developmental predictions and calling for theory conservatism.

Schwartz, B. D., \& Sprouse, R. A. (1996). L2 cognitive states and the full transfer/full access model. Second language research, 12(1), 40-72.

Slabakova, R. (this issue). The Scalpel Model of third language acquisition. International Journal of Bilingualism. 
Slabakova, R., \& Garcia Mayo, M. P. (2015). The L3 syntax-discourse interface. Bilingualism: Language and Cognition, 18(2), 208-226.

Vikner, S. (1995). Verb Movement and Expletive Subjects in the Germanic Languages. Oxford: Oxford University Press.

Ullman, M. (2001). The neural basis of lexicon and grammar in first and second language: the declarative/procedural model. Bilingualism: Language and Cognition, 4(2), $105-$ 122.

Westergaard, M. (2003). Unlearning V2. Transfer, markedness, and the importance of input cues in the acquisition of word order in English by Norwegian children. EUROSLA Yearbook, 3, 77-101.

Westergaard, M. (2007). English as a Mixed V2 Grammar: Synchronic word order inconsistencies from the perspective of first language acquisition. Poznan Studies in Contemporary Linguistics 43(2),107-131.

Westergaard, M. (2008). Acquisition and change: On the robustness of the triggering experience for word order cues. Lingua 118.12, 1841-1863.

Westergaard, M. (2009). The Acquisition of Word Order: Micro-cues, Information Structure and Economy. [Linguistik Aktuell/Linguistics Today 145], Amsterdam: John Benjamins. 
Westergaard, M. (2014). Linguistic variation and micro-cues in first language acquisition.

Linguistic Variation, 14(1), 26-45. 


\section{Appendix 1}

Table 4. Overview of test items.

\begin{tabular}{lllll}
\hline & Subject & Verb & Auxiliary & Adverb (frequency) \\
\hline 1. & Susan & eat & will & often \\
2. & Emma & drink & can & always \\
3. & Nina & cook & & rarely \\
4. & Peter & read & usually \\
5. & Jonny & tell & & sometimes \\
6. & Danny & ask & & never \\
\hline
\end{tabular}

\section{Appendix 2}

We fitted three generalized mixed effect models in order to estimate the effect of LANGUAGE GROUP (L1 Nor, 2L1 Nor-Rus, L1 Rus) and CONDITION (Adv-V, Aux-S), as well as their interaction, on the correctness of judgment. In the first model, we considered the participants' judgments of all sentences. The second model evaluated the judgments of grammatical sentences. The third model considered the judgments of ungrammatical 
sentences. Tables 5-7 summarize the fixed effects of the three models. We report estimates, standard errors (in parenthesis), odd ratios, $z$ values and $\operatorname{Pr}(>|z|)$.

Table 5. Fixed effects for Model 1 (all sentences).

\begin{tabular}{|c|c|c|c|c|}
\hline & $\begin{array}{l}\text { Estimates } \\
\text { (Std.error) }\end{array}$ & odd ratios & $\mathrm{z}$ value & $\operatorname{Pr}(>|z|)$ \\
\hline Intercept (Norwegian-Adverb) & $0.51(0.21)$ & 1.67 & 2.38 & $0.017 *$ \\
\hline Norwegian-Russian & $0.84(0.31)$ & 2.31 & 2.68 & $0.007^{* *}$ \\
\hline Russian & $1.46(0.32)$ & 4.31 & 4.57 & $4.85 \mathrm{e}-06^{* * *}$ \\
\hline Auxiliary & $1.35(0.30)$ & 3.86 & 4.58 & $4.72 \mathrm{e}-06^{* * *}$ \\
\hline Norwegian-Russian: Auxiliary & $-0.83(0.40)$ & 0.44 & -2.05 & $0.04^{*}$ \\
\hline Russian: Auxiliary & $-2.07(0.41)$ & 0.13 & -5.03 & $4.79 \mathrm{e}-07 * * *$ \\
\hline
\end{tabular}

Table 6. Fixed effects for Model 2 (grammatical sentences).

Estimates odd ratios $z$ value $\operatorname{Pr}(>|z|)$

(Std.error)

$\begin{array}{lllll}\text { Intercept (Norwegian-Adverb) } & 0.29(0.32) & 1.34 & 0.89 & 0.38\end{array}$




\begin{tabular}{lcccc} 
Norwegian-Russian & $0.51(0.38)$ & 1.67 & 1.32 & 0.19 \\
Russian & $1.69(0.46)$ & 5.42 & 3.65 & $0.0002 * * *$ \\
Auxiliary & $1.66(0.48)$ & 5.26 & 3.49 & $0.0005^{* * *}$ \\
Norwegian-Russian: Auxiliary & $-0.60(0.57)$ & 0.55 & -1.05 & 0.29 \\
Russian: Auxiliary & $-2.77(0.63)$ & 0.06 & -4.32 & $1.52 \mathrm{e}-05^{* * *}$ \\
\hline \multicolumn{2}{l}{ Significance codes: ${ }^{*} p<.05 * * p<.01 * * * p<.001$}
\end{tabular}

Table 7. Fixed effects for Model 3 (ungrammatical sentences).

\begin{tabular}{lllll}
\hline & Estimates & odd ratios & z value & $\operatorname{Pr}(>|z|)$ \\
& (Std.error) & & & \\
& & & & \\
\hline Intercept (Norwegian-Adverb) & $0.76(0.21)$ & 2.14 & 3.51 & $0.0005^{* * *}$ \\
Norwegian-Russian & $1.27(0.42)$ & 3.56 & 2.96 & $0.003^{* *}$ \\
Russian & $1.33(0.36)$ & 3.78 & 3.66 & $0.0002^{* * *}$ \\
Auxiliary & $-1.36(0.38)$ & 0.26 & 3.57 & $0.0004^{* * *}$ \\
Norwegian-Russian: Auxiliary & $-1.22(0.64)$ & 0.30 & -1.89 & $0.059^{\mathrm{a}}$ \\
Russian: Auxiliary & $-0.40(0.55)$ & 0.67 & -2.52 & $0.01^{*}$ \\
\hline
\end{tabular}

\footnotetext{
Significance codes: $* p<.05 * * p<.01 * * * p<.001$
} 
Table 8 presents details of the post-hoc multiple comparisons ( $R$ multcomp, Hothorn et al., 2008) for Models 1-3. We report estimates, standard errors (in parenthesis), and significance codes for $\operatorname{Pr}(>|z|)$.

Table 8. Simultaneous Tests for General Linear Hypotheses: Condition1 (Adv-V) \& Condition2 (Aux-S).

\begin{tabular}{|c|c|c|c|}
\hline Linear hypotheses & $\begin{array}{l}\text { Model } 1 \\
\text { (all sentences) }\end{array}$ & $\begin{array}{l}\text { Model } 2 \\
\text { (grammatical } \\
\text { sentences) }\end{array}$ & $\begin{array}{l}\text { Model } 3 \\
\text { (ungrammatical } \\
\text { sentences) }\end{array}$ \\
\hline Adverb: Nor-Rus - L1Nor $==0$ & $0.84(0.03)^{*}$ & $0.51(0.39)$ & $1.27(0.42)^{*}$ \\
\hline Adverb: L1Rus - L1Nor $==0$ & $1.47(0.32)^{* * *}$ & $1.68(0.46)^{* *}$ & $1.33(0.36)^{* *}$ \\
\hline Adverb: L1Rus - Nor-Rus $==0$ & $0.62(0.41)$ & $1.18(0.47)^{\mathrm{a}}$ & $0.05(0.48)$ \\
\hline Auxiliary: Nor-Rus - L1Nor $==0$ & $0.01(0.41)$ & $-0.08(0.46)$ & $0.04(0.64)$ \\
\hline Auxiliary: L1Rus - L1Nor $==0$ & $-0.60(0.38)$ & $-1.08(0.47)$ & $-0.07(0.55)$ \\
\hline Auxiliary: L1Rus - Nor-Rus $==0$ & $-0.61(0.46)$ & $-0.99(0.50)$ & $-0.11(0.69)$ \\
\hline
\end{tabular}

